\title{
Extraction Kinetics of Saponins from Quinoa Seed (Chenopodium quinoa Willd)
}

\author{
R. M. Torrez IrIGOYen ${ }^{a, b}$ AND S. A. Giner ${ }^{a, b, c^{*}}$ \\ ${ }^{a}$ Centro de Investigación y Desarrollo en Criotecnología de Alimentos (CIDCA). Facultad de Ciencias Exactas, \\ Universidad Nacional de La Plata, Calle 47 y 116 (1900)- La Plata, Provincia de Buenos Aires, Argentina \\ ${ }^{\mathrm{b}}$ Facultad de Ingeniería, Universidad Nacional de La Plata \\ ${ }^{\mathrm{c}}$ Comisión de Investigaciones Científicas de la Provincia de Buenos Aires, Argentina \\ ${ }^{*}$ Corresponding author \\ saginer@ing.unlp.edu.ar
}

Received: 12 December 2017; Published online: 18 October 2018

\begin{abstract}
Quinoa has higher protein content $(11-16 \% \mathrm{~m} / \mathrm{m})$ and better amino acid profile than cereals and represents a valuable resource for healthy nutrition. The aim of this work was to study the saponins extraction kinetics during washing of soaked quinoa. The experimental curves of saponins content as a function of time was measured at water temperatures of $20,40,60$, and $70^{\circ} \mathrm{C}$. A spectrophotometric method was proposed to determine total saponins content, while an unsteady state diffusional model was applied to this extraction problem, assuming strict internal control to the mass transfer rate. As a first analysis, the complete analytical solution for constant diffusion coefficient $\left(D_{\text {eff }}\right)$ using the initial radius $\left(R_{0}\right)$ provided an accurate predicted curve at each temperature. The diffusion coefficients (around $10^{-10} \mathrm{~m}^{2} \mathrm{~s}^{-1}$ ), were correlated with temperature using an Arrhenius-type relationship to obtain an activation energy $E_{a}$ of $16.9 \mathrm{~kJ} \mathrm{~mol}^{-1}$. The preliminary values of $E_{a}$ and preexponential factor $\left(D_{0}\right)$ thus obtained were used as initial values of a second, more robust fitting where the whole dataset of saponins concentrations as a function of time for all temperatures. The Arrhenius equation was directly inserted into the diffusional solution. The following parameters were obtained: $E_{a}=17.2 \mathrm{~kJ}$ $\mathrm{mol}^{-1}$ and, $D_{0}=3.232 \times 10^{7} \mathrm{~m}^{2} \mathrm{~s}^{-1}$, respectively with an overall $r^{2}=0.985$. Saponins content agreed well with experimental values. As the equation is capable of predicting saponin extraction times for various operating conditions, it can be used within equipment design schemes.
\end{abstract}

Keywords: Quinoa; Saponins; Diffusive model; Spectrophotometric method

\section{Introduction}

The quinoa (Chenopodium quinoa Willd) is an ancient crop of the Andean region of South America. It is considered a pseudo-cereal with high levels of protein and a good balance of essential amino acids (Food and Agriculture Organization, 2011; Escuredo, Martin, Moncada, Fischer, \& Hierro, 2014; Navruz-Varli \& Sanlier, 2016). In addition, the lipid fraction is rich in essential fatty acids, such as linoleic and $\alpha$-linolenic acids (Navruz-Varli \& Sanlier, 2016; Peiretti, Gai, \& Tassone, 2013) and, besides, quinoa has a high minerals content particularly calcium, magnesium, potassium, phosphorus and manganese, with high amounts of iron as well (Vega-Galvez et al., 2010). Having no gluten, quinoa is a food of choice for celiacs (Ridout, Price, Dupont, Parker, \& Fenwick, 1991). On these grounds, in recent years, quinoa seeds have become important to an extent that FAO declared 2013 as the International Year of Quinoa (Food and Agriculture 


\section{Nomenclature}

$\begin{array}{ll}D_{\text {eff }} & \text { Effective diffusive coefficient, } \mathrm{m}^{2} \mathrm{~s}^{-1} \\ D_{0} & \text { Pre-exponential factor, } \mathrm{m}^{2} \mathrm{~s}^{-1} \\ E_{a} & \text { Activation energy, } \mathrm{kJ} \mathrm{mol}^{-1} \\ n & \text { Number of data points } \\ r & \text { radial position, } \mathrm{m} \\ R_{g} & \text { Universal gas constant, } 8.314 \times 10^{-3} \mathrm{~kJ} \\ & \text { mol }^{-1} \mathrm{~K}^{-1} \\ R_{0} & \text { Initial particle radius, } \mathrm{m} \\ S & \text { saponins content, } \mathrm{kg} \quad 100 \mathrm{~kg} \quad \mathrm{dry} \\ & \text { matter } \\ t & \text { Washing process time, } \mathrm{s} \\ T_{w} & \text { Water temperature, in }{ }^{\circ} \mathrm{C}\end{array}$

$T_{k} \quad$ Water absolute temperature, $\mathrm{K}$ Greek symbols

$\pi \quad$ Dimensionless number

Subscripts

$0 \quad$ Initial

$e \quad$ Equilibrium

$w \quad$ Water

$m \quad$ average

$d \quad$ Dimensionless

exp Experimental

pred Predicted
Organization, 2013).

However, these seeds have saponins, triterpenoid glycosides concentrated in the seed coat, that affect the taste of quinoa and protein digestibility, so they must be removed before consumption (Kozioł, 1992; Francis, Kerem, Makkar, \& Becker, 2002). Traditionally, the saponins are removed by a solid-liquid extraction usually carried out domestically washing the seeds under running water with which saponins develop foam; as foam formation vanishes, washing is considered complete (Ridout et al., 1991). However, the saponins content that a human can consume in quinoa is still a topic of discussion in terms of its bitterness and negative biological effects (Chauhan, Eskin, \& Tkachuk, 1992; QuispeFuentes et al., 2013). Recently, a standard was issued by the Codex alimentarius which establish a value of $0.12 \% \mathrm{~m} / \mathrm{m}$ as a maximum limit to be considered convenient for consumption in quinoa with a moisture content of $13.5 \%$ w.b. which represents a $0.14 \%(\mathrm{~m} / \mathrm{m})$ in dry basis units (Codex Alimentarius, 2017).

Regarding the methodology for measuring the amount of saponins, Koziol (1991) developed a method based on measuring the foam height formed by adding quinoa seeds to water in a tube, which was agitated for a period of time. However, this method has some drawbacks because the production and stability of foam are dependent on the chemical structure and surfactant capacity of the saponins, presence of salts, $\mathrm{pH}$ and agitation method. Other authors, as San Martin and Briones (2000) and Quispe-Fuentes et al. (2013) utilized successfully the reversed-phase high performance liquid chromatography (RPHPLC) to determine saponins. This is a wellestablished method in the pharmaceutical industry due to its high accuracy and precision. However, suitable standards of saponins are necessary for correct identification of the components and their quantitative determination (Ruales \& Nair, 1993). On the other hand, Nickel, Spanier, Botelho, Gularte, and Helbig (2016) studied the effect of different types of processing (i.e.: washing, cooking and toasting) on the saponins content of quinoa and applied a spectrophotometric method to determine the total saponins content with good results. The basic principle of this method is the reaction of oxidized triterpene saponins with vanillin. Sulfuric acid is used as oxidant and the distinctive colour of the reaction is purple (Hostettmann \& Marston, 1995). This method is simple, fast and inexpensive to 
operate. However, some factors as the selection of standards and the optimum wavelength should be considered before applying this technique (Cheok, Salman, \& Sulaiman, 2014).

Authors such as Ridout et al. (1991), Koziol (1991) and Nickel et al. (2016) investigated the effect of different treatments on the saponins content from quinoa using one of methods referred previously; nevertheless the information was limited only to the initial and final values for this compound. With respect to the saponin extraction kinetics few works were found in literature. Quispe-Fuentes et al. (2013) developed a diffusive model, considering spherical geometry, for the kinetics of saponins extraction in quinoa seeds during washing, obtaining accurate predictions. These authors utilized a chromatographic method for saponins quantification. It is possible that products experience swelling and thus structural modifications during washing (or soaking). From the technological point of view (for instance to develop equations of use in automatic control algorithms) simplified models as the analytical solutions of the unsteady state diffusion equation can be tested to represent the phenomenon (Torrez Irigoyen \& Giner, 2014). Although information on the nutritional potential of quinoa has been published (Kozioł, 1992; Vega-Galvez et al., 2010; Navruz-Varli \& Sanlier, 2016), only limited information is available on the kinetics of saponins extraction.

Therefore, the objective of this work is to study saponins extraction kinetics applying analytical solutions of the diffusion equation. Saponins were experimentally determined by a spectrophotometric technique. Knowledge of the kinetic behaviour may contribute to improve the understanding of the extraction mechanism and is useful for design purposes, since the diffusional model can be employed for estimating the extraction time to reach a safe saponins content for human consumption.

\section{Materials and Methods}

\section{$2.1 \quad$ Material}

Quinoa grains of the CICA variety, provided by the INTA EEA Famaillá, Provincia de Tucumán
Argentina (Famaillá Experimental Station of the National Institute of Agricultural Technology, Province of Tucumán) were utilized. Moisture content at reception was $0.111 \mathrm{~kg}$ water $\mathrm{kg}$ dry matter $^{-1}$. The experimental work carried out can be described by the flow sheet shown in Fig. 1.

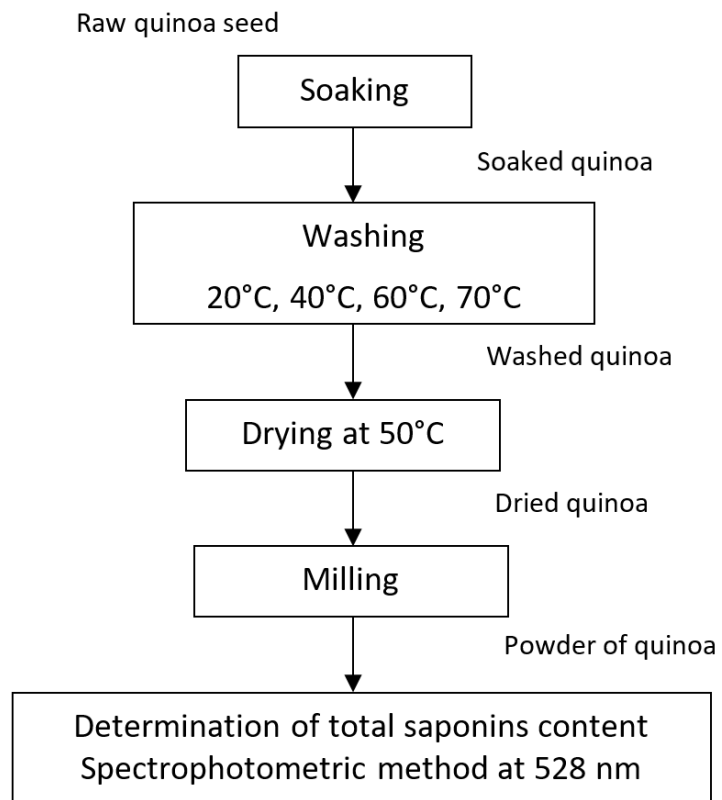

Figure 1: Flowsheet representing the experimental plan followed in this work

\section{$2.2 \quad$ Soaking}

Seeds were visually inspected to remove foreign materials and then immersed in distilled water, using a water-to-quinoa mass ratio of $5: 1$, and allowed to soak for $120 \mathrm{~min}$. Figure 2 shows the characteristics dimensions for soaked quinoa seed measured by a digital caliber.

\section{$2.3 \quad$ Washing}

Experimental curves of quinoa moisture and total saponins content as a function of time were measured in a shaking water bath at 20, 40,60 and $70^{\circ} \mathrm{C}$. The grains were loaded in a steel bas- 

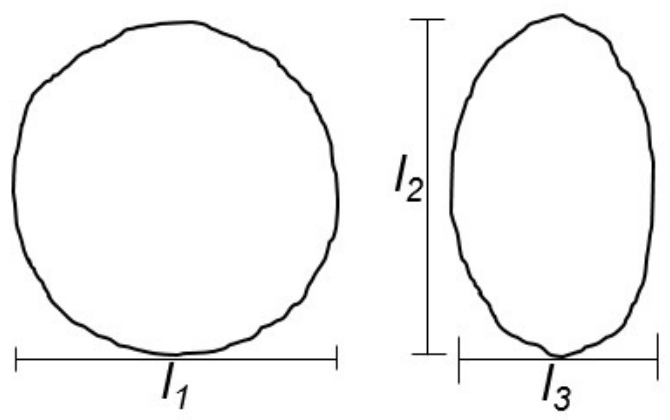

Figure 2: Drawing of front view and plan view of the quinoa seed and their axis measured utilizing a digital caliber. $l 1: 2.301 \pm 0.113 \mathrm{~mm}, l 2: 2.198$ $\pm 0.077 \mathrm{~mm}$ and $l 3: 1.371 \pm 0.408 \mathrm{~mm}$

ket (initial mass of seeds: $60 \pm 0.4 \mathrm{~g}$ ) and immersed in the water bath. Samples were removed at various times between 5 and 70 min for moisture content and total saponins determination.

\section{$2.4 \quad$ Drying}

In order to obtain powder suitable for saponins content determination a thin layer of soaked and washed quinoa was dried by placing the seeds in a tray inside a mechanical convection oven set at $50^{\circ} \mathrm{C}$ until reaching a final moisture content of $0.117 \pm 0.001 \mathrm{~kg}$ water $\mathrm{kg}$ dry matter $^{-1}$. Moderate temperatures were considered for the drying step in order to avoid undesirable reactions such as Maillard (Brožková et al., 2018).

\subsection{Determination of moisture content}

Moisture content was determined in triplicate by the AOCS Ac 2-41 whole grain method $\left(130^{\circ} \mathrm{C}\right.$, atmospheric pressure, $3 \mathrm{~h}$ ) in a mechanical convection oven (air velocity, $0.25 \mathrm{~m} \mathrm{~s}^{-1}$ ) Sanjor Model SL30SDB, Argentina.

\subsection{Milling}

The dried samples were milled for three minutes in a grinder (Peabody, Pe-mc9100, China) and reduced to a powder sieved with a mesh size of 80 which correspond to a particle size of 0.177 $\mathrm{mm}$.

\subsection{Determination of saponins content by spectrophotometric analysis}

For extraction of saponins, $2.5 \mathrm{~g}$ of sample was added to $25 \mathrm{~mL}$ of $50 \%(\mathrm{v} / \mathrm{v})$ ethanol and left for $30 \mathrm{~min}$ at room temperature. Subsequently, the extracts were filtered through qualitative filter paper (grammage $80 \mathrm{~g} \mathrm{~m}^{-2}$ ) into $25 \mathrm{ml}$ glass volumetric flask and topped up to volume with $50 \%$ Ethanol. The analysis was carried out by adding $1 \mathrm{~mL}$ of the diluted extract (1:20 dilution) to 3.5 $\mathrm{mL}$ of the Lieberman-Buchard reagent $(16.7 \%$ of acetic anhydride in concentrated sulfuric acid). The solution was vortexed and left to stand in the dark for 30 min at room temperature, before being placed in a spectrophotometer set at 528 nm. Quantification was performed with a standard of saponins provided by Biopack Chemical products. The calibration curve was performed at $50-350 \mu \mathrm{g} \mathrm{mL}^{-1}$ and the results were expressed as $\mathrm{kg}$ saponins per $100 \mathrm{~kg}$ dry matter (Gianna, Manuel Montes, Luis Calandri, \& Alberto Guzman, 2012; Nickel et al., 2016). All measurements were carried out three times.

\section{Mathematical modeling of saponins extraction}

\subsection{Microscopic mass balance with diffusional transport of mass}

In general, taking the grain volume as a system and assuming mass transport by molecular diffusion, the microscopic mass balance can be expressed in the following way for constant volume of seed (Crank, 1975)

$$
\frac{\partial S_{I}}{\partial t}=\nabla\left(D_{e f f} \nabla S_{I}\right)
$$

where $D_{\text {eff }}$ is the effective diffusion coefficient of saponins relative to the dry matter. For radial water flux in spherical geometry, consider- 
ing diffusion coefficient independent of saponins content, Eq. 1 can be developed to give (Pabis, Jayas, \& Cenkowski, 1998).

$$
\frac{\partial S_{I}}{\partial t}=D_{e f f}\left(\frac{\partial^{2} S_{I}}{\partial r^{2}}+\frac{2}{r} \frac{\partial S_{I}}{\partial r}\right)
$$

This equation holds true for each internal point of the solid, and gives the local value of the diffusing component $S_{l} \mathrm{~kg}$ saponins $100 \mathrm{~kg}$ dry matter ${ }^{-1} \mathrm{~s}^{-1}$ as a function of time $t$ in seconds and the radial coordinate $r$ in $\mathrm{m}$, whose axis is always normal to the surface and whose origin is placed at the center of symmetry.

\section{Initial and boundary conditions in mass transfer}

The initial and boundary conditions to solve the partial differential equation Eq. 2, are the following: Initial condition:

$$
t=0 ; S_{L}=S_{0} ; 0 \leq r \leq R_{0}
$$

where $S_{0}$ is the initial saponins content and $R_{0}$ is the initial seed radius (average value of 2141.652 $\times 10^{-3} \mathrm{~m}$ ). Boundary condition in the particle centre: The water flux is zero by symmetry

$$
r=0 ; \frac{\partial S_{L}}{\partial r}=0 ; t>0
$$

Boundary condition at the surface The surface boundary condition can be represented as follows:

$$
r=R_{0} ; S_{s}=S_{e} ; t>0
$$

where $S_{s}$ is the particular value of $S_{l}$ at the surface. This represents that during washing the external resistance may be considered negligible compared to the internal, so a prescribed boundary condition could be proposed which means a strict internal control for mass transfer (QuispeFuentes et al., 2013).

\section{Analytical solution of the diffusion equation}

The unsteady state diffusion equation for spheres (Eq. 2), with the initial condition given by Eq. 3 and boundary conditions provided by equations 4 and 5 , can be analytically solved after integration in the sphere volume to give the average saponins content $S_{m}$ as a function of time (Quispe-Fuentes et al., 2013).

$$
S_{d}=\frac{S_{m}-S_{e}}{S_{0}-S_{e}}=\frac{6}{\pi^{2}} \sum_{n=1}^{n=\infty} \frac{1}{n^{2}} e^{-n^{2} \pi^{2}} \frac{D_{e f f} t}{R_{0}^{2}}
$$

where $S_{d}$ is the dimensionless saponins content, $S_{e}$ equilibrium saponins content in $\mathrm{kg}$ saponins $100 \mathrm{~kg}$ dry matter ${ }^{-1}$ and $n$ number of data points. To implement the analysis, Eq. 6 was solved for $S_{m}$

$$
S_{m}=S_{e}+\left(S_{0}-S_{e}\right) \frac{6}{\pi^{2}} \sum_{n=1}^{n=\infty} \frac{1}{n^{2}} e^{-n^{2} \pi^{2} \frac{D_{e f f} t}{R_{0}^{2}}}
$$

With the purpose to determine the effective diffusion coefficient ten terms of the series was applied to fit the experimental data.

\section{Dependence of the diffusion coefficient with temperature}

With the aim of estimating the effect of temperature on $D_{\text {eff }}$ the natural logarithms of the experimental diffusion coefficients were plotted as a function of the reciprocal of the water bath absolute temperature by means of an Arrhenius-type equation, as proposed in (Eq. 8)

$$
\operatorname{Ln} D_{e f f}=\operatorname{Ln} D_{0}-\frac{E_{a}}{R_{g} T_{k}}
$$

Where $T_{k}$ stands for the absolute water temperature in $K$. Symbol $D_{0}$ represents the pre exponential factor in $\mathrm{m}^{2} \mathrm{~s}^{-1}$, while $E_{a}$ is the activation energy in $\mathrm{kJ} \mathrm{mol}^{-1}$, being $R_{g}$ the gas constant, $8.314 \times 10^{-3} \mathrm{~kJ} \mathrm{~mol}^{-1} \mathrm{~K}^{-1}$.

\section{$3.2 \quad$ Statistical analysis}

Triplicate experiments were carried out for each determination, measuring saponins content. Different conditions were compared by the Tukey's test (Montgomery, 1991), at a confidence level of $95 \%$. The goodness of fit was evaluated by two indicators, to have prediction errors expressed in the same units as the fitted variable, the root 
mean square error $(R M S E)$.

$$
R M S E=\sqrt{\frac{\sum_{i=1}^{N}\left(Y_{p r e d, i}-Y_{e x p, i}\right)^{2}}{N}}
$$

Where $y_{\text {exp }, i}$ stands for an experimental value and $y_{\text {pred,i }}$ represents the corresponding predicted number. The other statistical indicator is the coefficient of determination $r^{2}$, which was computed by using the following equation:

$$
r^{2}=1-\frac{\sum_{i=1}^{N}\left(Y_{e x p, i}-Y_{p r e d, i}\right)^{2}}{\sum_{i=1}^{N}\left(Y_{e x p, i}-Y_{m}\right)^{2}}
$$

Where $y_{m}$ is the average value of the experimental data.

\section{Results and discussion}

\subsection{Experimental saponins extraction curves}

The Tukey's test of that three determination of the experimental saponins content did not present significant differences at a confidence level of $95 \%$ in all cases. Experimental extraction curves showing the average seed saponins content $\left(S_{m}\right)$ as a function of time, in $\mathrm{kg}$ Saponins $100 \mathrm{~kg}$ dry matter $^{-1}$ are presented in Fig. 2. The initial saponins content determined by the spectrophotometric method was $0.179 \%(\mathrm{~m} / \mathrm{m})$ which correspond with the bitter variety of this seed, saponins content $>0.11 \% \mathrm{~m} / \mathrm{m}$ (Nickel et al., 2016). However, after the soaking process a value of $0.156 \%(\mathrm{~m} / \mathrm{m})$ was measured. For sake of clarity, henceforth the values will be expressed in dry basis units, in this manner the $0.156 \%$ $(\mathrm{m} / \mathrm{m})$ becomes to $0.311 \%$ d.b. In this work this last value was considered as initial saponins content.

As observed in Fig. 3, saponins content falls with time in all cases with decreasing slope. This suggests an internal control for mass transfer as well as a gradual approach towards equilibrium values. As is shown in Fig. 3 the saponins content decrease faster during the first 5 min of process. From this time and until $40 \mathrm{~min}$ is observed a gradual decrease in the content reaching an equilibrium saponins content above this last process time. Besides, this decrease is faster at higher temperatures. Quispe-Fuentes et al. (2013) have reported a similar behavior during saponins extraction from quinoa seeds in a comparable temperature range. At the final process time the saponins content values are lower than the 0.140 $\%$ expressed in dry matter units proposed by the Codex Alimentarius (2017).

However, the scarce literature found agrees in that the effectiveness of saponins elimination can be expressed as a percentage of total extraction (Erramouspe, Armada, \& Molina, 2013; Cheok et al., 2014). In this work, the final value for saponins content represents, in all experiments, an extraction percentage higher than $80 \%$ against the initial content ( $S_{\text {finalcontent }}$ / $S_{\text {initialvalue }} * 100$ ). Nickel et al. (2016) used the spectrophotometric method and found a percentage of $17 \%(\mathrm{p} / \mathrm{p})$ for quinoa seeds washed during $15 \mathrm{~min}$. On the other hand, authors as Ridout et al. (1991) and Ruales and Nair (1993) who analyzed the saponins content after different treatments have reported similar extraction percentages. However, these authors used the gas chromatography and HPLC methods, respectively for saponins quantification. It is difficult to compare the saponins content between different works because no official method exists so far (Codex Alimentarius, 2017).

The amount of elimination of saponins content obtained by different methods can be comparable. However, the absence of an official method to quantify these compounds in products intended for human consumption is not yet available, except for the recent standard established by the Codex Alimentarius.

\subsection{Analytical series solution of diffusion}

Table 1 lists the parameters resulting from the fitting of ten terms of the analytical series solution model (Eq. 7) to the data of Fig. 3 by a nonlinear least squares quasi newton method (Systat version 12, 2007). The table also includes statistical indices of goodness of fit. Values of $r^{2}$ and $R M S E$ are highly satisfactory.

Parameters of goodness of fit, $r^{2}$ and RMSE in Table reftable:1 indicate that the model (Eq. 7) 


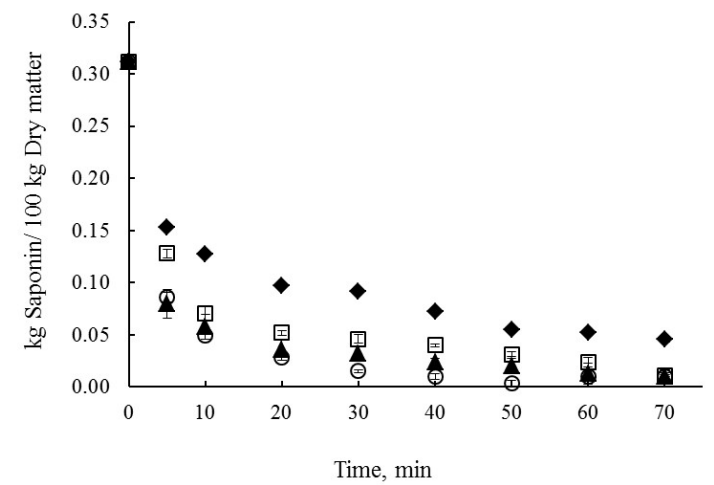

Figure 3: Experimental curves of quinoa saponins content as a function of time, at different water temperatures: $(\checkmark) 20^{\circ} \mathrm{C},(\square) 40^{\circ} \mathrm{C}$, (ム) $60^{\circ} \mathrm{C}$ and $(\circ) 70^{\circ} \mathrm{C}$

provides an adequate description of the experimental behavior (Eq. 7). The values for Effective diffusivity coefficient are in agreement with those presented by Abdelkader (1992) who studied the loss of glucose from potatoes and Varzakas, Leach, Israilides, and Arapoglou (2005) who developed a research on the theoretical and experimental approaches for the determination of solute effective diffusivities in foods. Figure 4 shows the predictions of Eq. 7 with the parameters of Table reftable: 1 together with the experimental data.

The Fig. 4 shows a reasonably good prediction for all cases. The agreement between the experimental data and predicted values were obtained in spite of the assumptions made of constant diffusion coefficient and negligible shrinkage which are required to obtain the analytical solution (Eq. 7). The rapid elimination of saponins from quinoa seeds was favored by the previous stage of soaking, which is recommended by several authors with the purpose of facilitating the saponins extraction. Authors as Chauhan et al. (1992) and Nickel et al. (2016) attribute this effect to the hydration of particles, which allows water to penetrate in the particle, thus facilitating the release of saponins by diffusion. Secondly, the presence of saponins on the seed coat may also contribute to an easier removal of these compounds (Koziol, 1991; Vega-Galvez et al., 2010).

As the temperature increased, extraction of saponins was faster. However, for 60 and $70^{\circ} \mathrm{C}$, at the end of the process, the appearance of seeds became altered losing the seed coat and germ. Even when proteins and carbohydrates experience a high degree of hydration during washing. However, the total content of protein in quinoa seed varied between 10 and $13 \%$ d.b. while the starch content in this product is five times as large, in the range of $58-66 \%$ d.b. (Koziol, 1992; Food and Agriculture Organization, 2011; Srichuwong et al., 2017). From this point of view, it is possible to ascribe the loss of structure more to starch gelatinization than to protein denaturation. Authors as Kashaninejad, Maghsoudlou, Rafiee, and Khomeiri (2007) who investigated the hydration kinetics of a starchy grain as rice at different temperatures, suggested that soaking must be conducted at temperatures below that of starch gelatinization $\left(65-70^{\circ} \mathrm{C}\right)$ to preserve kernel structure. For this reason, it is considered that a temperature of $50^{\circ} \mathrm{C}$ should not be exceeded during the process (Jan, Panesar, Rana, \& Singh, 2017; Li \& Zhu, 2017). Besides, authors as Mota et al. (2016) who studied the loss of soluble solids (some proteins, minerals, some vitamins) during soaking in water at several temperatures for different seeds suggested that long periods of time in hot water may contribute to a higher reduction of water-soluble nutritional compounds in quinoa seeds.

\subsection{Dependence of the diffusion coefficient with temperature}

An Arrhenius-type Equation was fitted to data of the natural logarithm of the experimental diffusion coefficients $\left(\operatorname{Ln} D_{e f f}\right)$ as a function of the reciprocal of the water absolute temperature of $1 / \mathrm{T}_{k}$, that is, $(1 /(\mathrm{Tw}+273.15))$, by means of an Arrhenius-type equation (Eq. 7). The symbol $T_{w}$ stands for the water temperature in ${ }^{\circ} \mathrm{C}$. The $E_{a}$ is a measure of the effect of temperature on the diffusion coefficient.

Predictions shown in Fig. 5 are in good agreement with the experimental coefficients. Results 


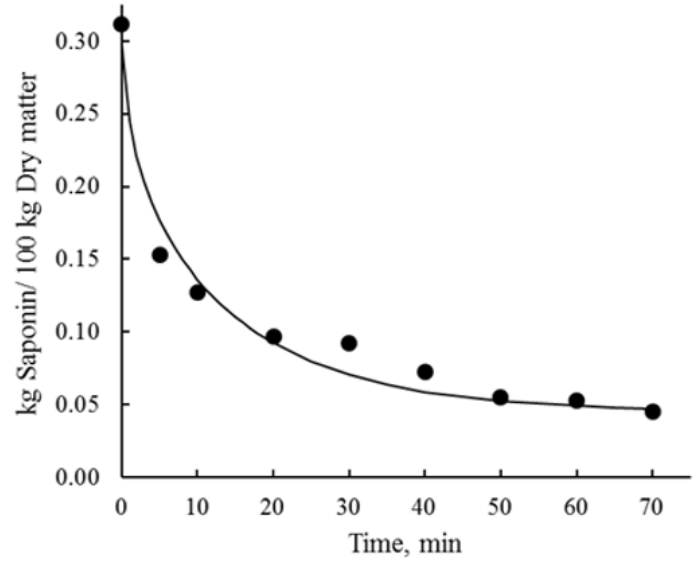

(a)

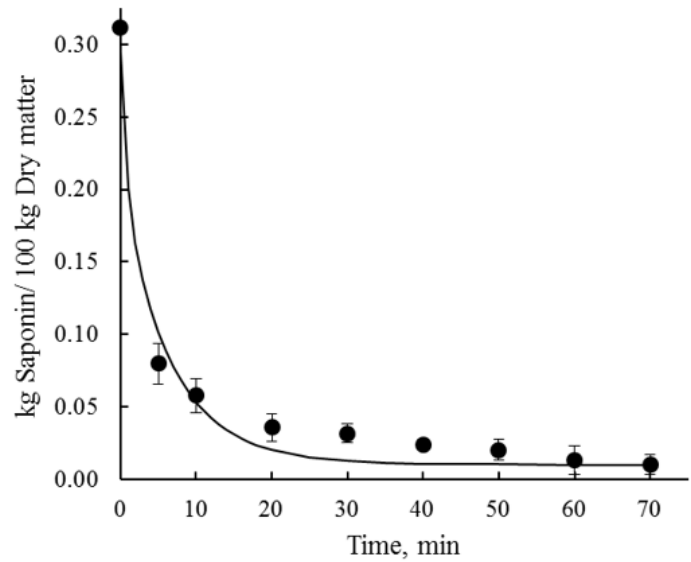

(c)

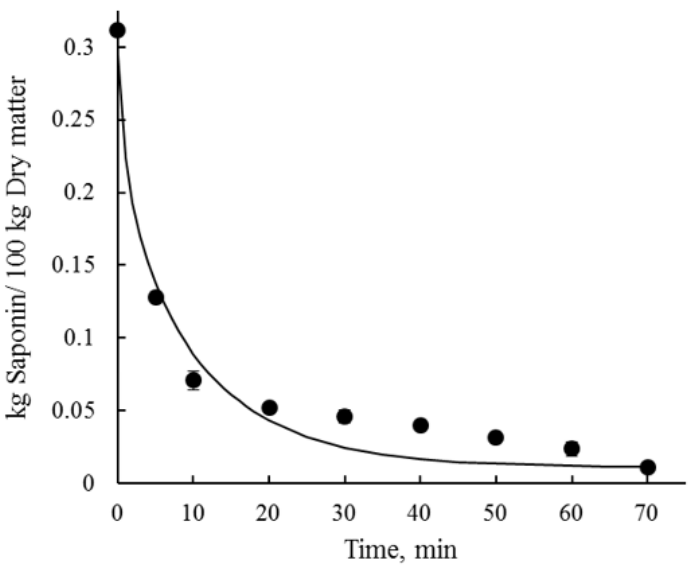

(b)

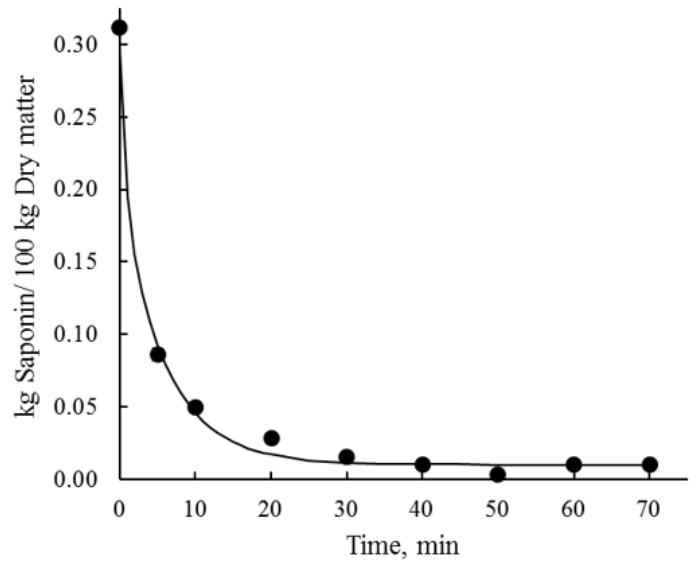

(d)

Figure 4: Saponins content curves from soaked quinoa during washing treatment. Experimental data (symbols), and predicted values (-) by f the analytical solution (Eq.6), for water temperatures of: (a) $20^{\circ} \mathrm{C}$, (b) $40^{\circ} \mathrm{C}$, (c) $60^{\circ} \mathrm{C}$ and (d) $70^{\circ} \mathrm{C}$

Table 1: Effective diffusion coefficients of saponins in quinoa determined by fitting the Eq. 6 to experimental data and their Asymptotic Standard Estimation (S)

\begin{tabular}{ccccc}
\hline$T^{o} C$ & $D_{\text {eff }} \times 10^{-10} \mathrm{~m}^{2} / \mathrm{s}$ & $S\left(D_{\text {eff }}\right) \times 10^{-11}$ & $r^{2}$ & $R M S E$ \\
\hline 20 & 2.848 & 1.962 & 0.983 & 0.013 \\
40 & 4.012 & 3.115 & 0.978 & 0.016 \\
60 & 6.665 & 5.837 & 0.979 & 0.014 \\
70 & 7.538 & 4.088 & 0.995 & 0.008 \\
\hline
\end{tabular}


from the fitting of Eq.7 were: $E_{a}=16.9 \mathrm{~kJ} \mathrm{~mol}^{-1}$ and $D_{0}=2.875 \times 10^{-7} \mathrm{~m}^{2} \mathrm{~s}^{-1}$, with a high coefficient of determination, $\mathrm{r}^{2}=0.987$. The activation energy for saponins extraction was comparable to that obtained in a similar temperature range by Quispe-Fuentes et al. (2013) during saponins extraction and Chi et al. (2006) who studied the leaching of flavonoids from vegetables.

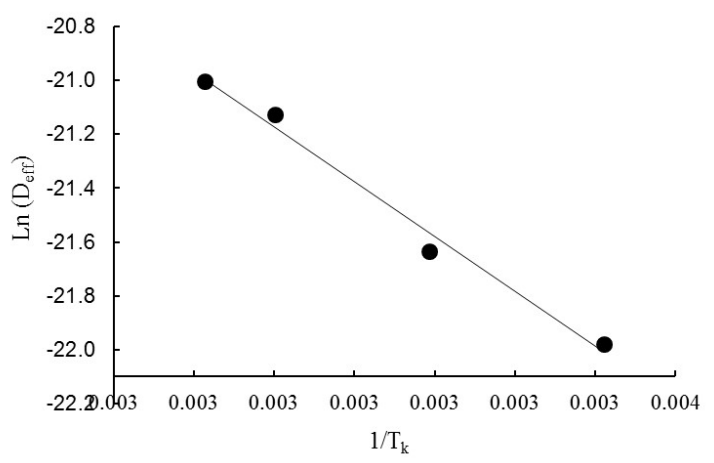

Figure 5: Dependency of the experimental diffusion coefficient with water temperature (symbols) together with predictions by an Arrheniustype equation fitted to them (solid line)

\subsection{A more accurate method to calculate the activation energy for saponins extraction process}

In this section, a second method of fitting the analytical solution to whole dataset was tested to obtain an activation energy $\left(E_{a}\right)$ that can be determined with more degrees of freedom. With this purposes the Eq.7 was rewritten in the following way:

$$
\begin{aligned}
& S_{m}=S_{e}+\left(S_{0}-S_{e}\right) \frac{6}{\pi^{2}} \sum_{n=1}^{n=\infty} \frac{1}{n^{2}} . \\
& e^{-n^{2} \pi^{2} \frac{\left(D_{0} e^{\left.\frac{E_{a}}{8.314} \frac{1}{\left(T_{w}+273.15\right)} t\right)}\right.}{R_{0}^{2}}}
\end{aligned}
$$

The effective diffusion coefficient was replaced directly by the Arrhenius equation, Eq. 8 to find an overall activation energy $\left(E_{a}\right)$ ) and a pre-exponential factor $\left(D_{0}\right)$. This equation was solved by a nonlinear least squares quasi newton method for whole dataset, using as initial values for $E_{a}$ and $D_{0}$, those obtained previously in section 4.3.

An overall activation energy $\left(E_{a}\right)$ of $17.2(2.6)$ $\mathrm{kJ} \mathrm{mol}^{-1}$ and a pre-exponential factor equal to $3.232 \times 10^{-7}\left(3.234 \times 10^{-9}\right) \mathrm{m}^{2} \mathrm{~s}^{-1}$ were estimated with a global coefficient of determination of 0.985 (Systat 12, 2007), which is higher than the average coefficient of determination of the fittings shown in Table reftable:1. The values presented between brackets correspond to the asymptotic standard error of the parameters.

The consideration of more degrees of freedom in a single fitting stage allows a more accurate determination of the activation energy and then a more reliable influence of temperature on for the process. Some authors as van Boekel (2008) who works about the estimation of kinetics parameters on some quality food process recommend the use of all data available in order to estimate the activation parameters with more precision.

The predictions obtained by this second fitting procedure were satisfactory and the figures obtained, between predicted and experimental data, were almost coincident to those shown in Figure (4). Therefore, to avoid repetition, it was considered that it was more than sufficient to inform the statistical parameters of the second fitting procedure, the overall coefficient of determination $\left(r^{2}=0.985\right)$ and the asymptotic standard error (between brackets) for each parameter $E_{a}=17.2(2.6) \mathrm{kJ} \mathrm{mol}^{-1}$ and $D_{0}=3.232 \times 10^{-7}$ $\left(3.234 \times 10^{-9}\right) \mathrm{m}^{2} \mathrm{~s}^{-1}$.

In order to study the rate of the extraction process, Eq.12 was derived with respect to time, and the following equation was obtained:

$$
\begin{aligned}
\frac{d S_{m}}{d t}= & -\left(S_{0}-S_{e}\right) \frac{6}{R_{0}^{2}} D_{0} e^{-\frac{E_{a}}{R_{g} T_{k}}} \\
& \sum_{n=1}^{n=\infty} e^{-\frac{1}{n^{2}} \pi^{2} D_{0} e^{-\frac{E_{a}}{R_{g} T_{k}} \frac{t}{R_{0}^{2}}}}
\end{aligned}
$$

Figure 6 show the saponins extraction rates estimated from experimental saponins contents, and the predicted values a fair agreement is achieved. 


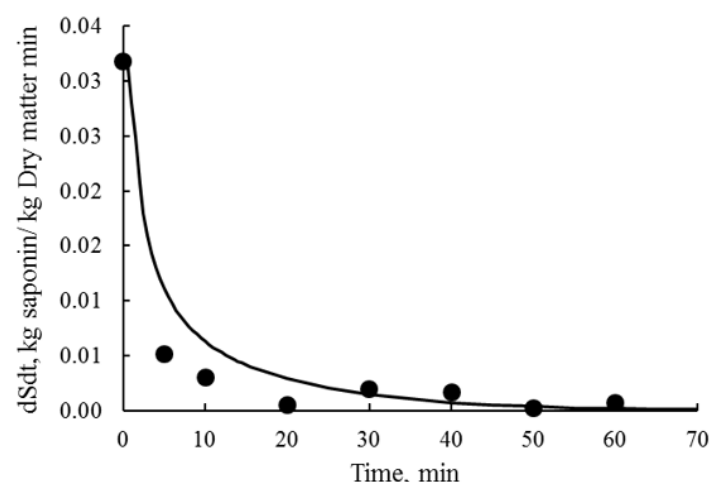

(a)

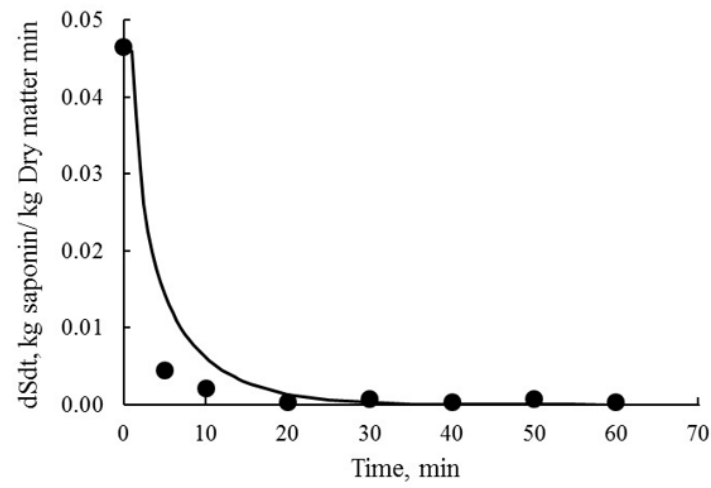

(c)

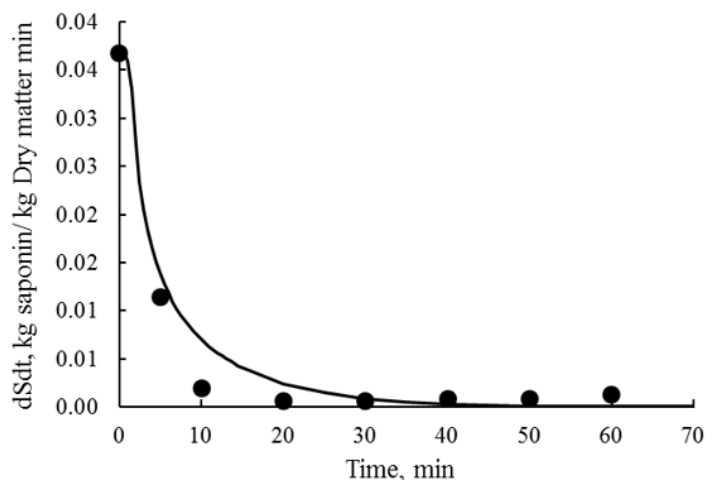

(b)

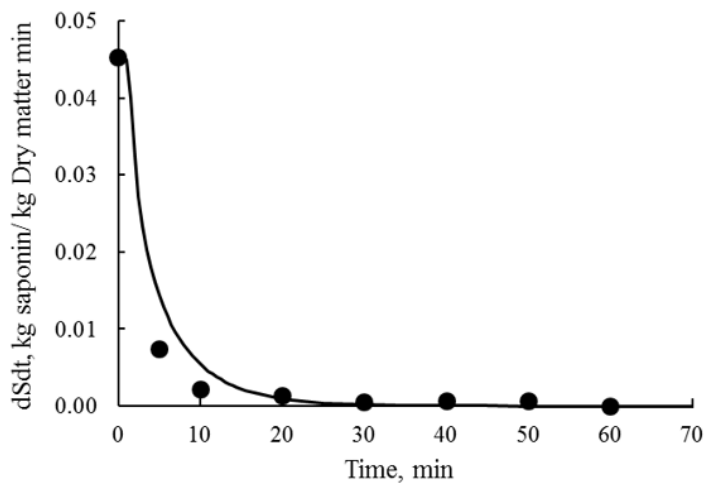

(d)

Figure 6: Saponins extraction rate $\left(-d S_{m} / d t\right), \mathrm{kg}$ saponins / kg dry matter min, obtained from (symbols) values obtained from experimental measurement and (solid line) predicted by the derivative of the diffusive model with respect to time for various water temperatures

The deviation observed at the beginning may be due to the error involved in calculating the experimental derivatives, which are approximated by two point forward finite differences.

Figure 6 shows that the saponins extraction rate is faster between in the first part of the process, which is then followed by a phase of much slower transfer rate. Lucas, Le Ray, and Mariette (2007) and Machado, Oliveira, and Cunha (1999) who studied the water absorption and solute leaching during soaking of different breakfast cereals reports a similar behavior.

\section{Conclusions}

In this work, the experimental extraction kinetics of saponins from quinoa seeds was studied at various water temperatures to improve the understanding of this process.

The spectrophotometric method was adequate to determine the total saponins content. From this study, the treatment carried out at $40^{\circ} \mathrm{C}$ for 6 min, can be considered optimum to reach a safe level of saponins for human consumption without visible damage to the seed.

An unsteady state diffusional model was proposed with strict internal control to the mass transfer rate, assuming constant diffusion coef- 
ficient and using the initial particle size during the process. The complete analytical solution of the diffusion equation provided reasonably accurate predictions of the experimental curves.

The experimental diffusion coefficients determined in this work were correlated as a function of water temperature by means of an Arrheniustype equation. Both the values of the diffusion coefficient (around $10^{-10} \mathrm{~m}^{2} \mathrm{~s}^{-1}$ ) and the activation energy (about $16.9 \mathrm{~kJ} \mathrm{~mol}^{-1}$ ) are within the ranges expected for similar processes.

A second, more general method for fitting the diffusional model to the entire set of data involved the inclusion of the Arrhenius equation inside the diffusional model to directly fit an overall activation energy $\left(E_{a}\right)$ of $17.2 \mathrm{~kJ} \mathrm{~mol}^{-1}$ and a preexponential factor equal to $3.232 \times 107 \mathrm{~m}^{2} \mathrm{~s}^{-1}$. A slightly more accurate prediction was obtained compared with the first fitting method.

In future work, a model similar to that developed here will be combined with another model for water diffusion into the grain. In addition, leaching of minerals will be measured to know the extent of this possible phenomenon. Such a model, combined with mass balances that include the water increase content, will be useful for equipment design, by predicting saponins extraction times for different operating conditions.

\section{References}

Abdelkader, Z. M. (1992). Effect of blanching on the diffusion of glucose from potatoes. Nahrung-Food, 36(1), 15-20.

Brožková, I., Zapletal, T., Kroutilová, L., Hájek, T., Moťková, P., \& Červenka, L. (2018). The effect of soaking regime and moderate drying temperature on the quality of buckwheat-based product. Journal of Cereal Science, 81, 15-21. doi:10.1016/j.jcs. 2018.01.015

Chauhan, G. S., Eskin, N. A. M., \& Tkachuk, R. (1992). Nutrients and antinutrients in quinoa seed. Cereal Chemistry, 69(1), 8588.

Cheok, C. Y., Salman, H. A. K., \& Sulaiman, R. (2014). Extraction and quantification of saponins: a review. Food Research Interna- tional, 59, 16-40. doi:10.1016/j.foodres. 2014.01.057

Chi, R. A., Tian, J., Gao, H., Zhou, F., Liu, M., Wang, C. W., \& Wu, Y. X. (2006). Kinetics of leaching flavonoids from pueraria lobata with ethanol. Chinese Journal of Chemical Engineering, 14(3), 402-406. doi:10.1016/ S1004-9541(06)60091-8

Codex Alimentarius. (2017). Norma en estudio No CL 2017/44-CPL. Retrieved from http : / / www . fao . org / faowho codexalimentarius / sh - proxy / en / ? lnk = $1 \% 5 \mathrm{C} \& \mathrm{url}=\operatorname{https} \% 5 \mathrm{C} \% 253 \mathrm{~A} \% 5 \mathrm{C} \%$ $252 \mathrm{~F} \% 5 \mathrm{C} \% 252 \mathrm{Fworkspace}$. fao . org $\%$ $5 \mathrm{C} \% 252 \mathrm{~F}$ sites $\% 5 \mathrm{C} \% 252 \mathrm{~F}$ codex $\% 5 \mathrm{C} \%$ $2 \%$ 2052FCircular \% 5C \% 252520Letters \% $5 \mathrm{C} \% 252 \mathrm{FCL} \% 5 \mathrm{C} \% 2525202017-81 \% 5 \mathrm{C} \%$ 252Fcl17_81e.pdf

Crank, J. (1975). The mathematics of diffusion. Oxford University Press.

Erramouspe, P. L. J., Armada, M., \& Molina, S. E. G. (2013). Propiedades físicoquímicas, estructurales y de calidad en semillas de quinua (chenopodium quinoa) variedad cica, con evaluación de la eficiencia de un proceso artesanal de escarificación en seco. Revista Ciencia y Tecnología de los Cultivos Industriales, 3(5), 71-79. Retrieved from https://inta.gob.ar/ sites/default/files/script-tmp-inta-revistaciencia-y-tecnologa-de-los-cultivos-indu_4. pdf

Escuredo, O., Martin, M. I. G., Moncada, G. W., Fischer, S., \& Hierro, J. M. H. (2014). Amino acid profile of the quinoa (chenopodium quinoa willd.) using near infrared spectroscopy and chemometric techniques. Journal of Cereal Science, 60(1), $67-74$.

Food and Agriculture Organization. (2011). Quinoa: an ancient crop to contribute to world food security. technical report. regional office for latin america and the caribbean. Retrieved from http://www . fao.org/docrep/017/aq287e/aq287e.pdf

Food and Agriculture Organization. (2013). Food and agriculture organization of the united nations regional office for latin america and the caribbean. International 
Year of Quinoa Secretariat. Retrieved from http://www.fao.org/quinoa-2013/en/

Francis, G., Kerem, Z., Makkar, H. P. S., \& Becker, K. (2002). The biological action of saponins in animal systems: a review. British Journal of Nutrition, 88(6), 587605. doi:10.1079/BJN2002725

Gianna, V., Manuel Montes, J., Luis Calandri, E., \& Alberto Guzman, C. (2012). Impact of several variables on the microwave extraction of chenopodium quinoa willd saponins. International Journal of Food Science and Technology, 47(8), 1593-1597. doi:10.1111/j.1365-2621.2012.03008.x

Hostettmann, K. \& Marston, A. (1995). Chemistry and pharmacology of natural products: saponins. Cambridge University Press.

Jan, K. N., Panesar, P. S., Rana, J. C., \& Singh, S. (2017). Structural, thermal and rheological properties of starches isolated from indian quinoa varieties. International Journal of Biological Macromolecules, 102, 315322. doi:10.1016/j.ijbiomac.2017.04.027

Kashaninejad, M., Maghsoudlou, Y., Rafiee, S., \& Khomeiri, M. (2007). Study of hydration kinetics and density changes of rice (tarom mahali) during hydrothermal processing. Journal of Food Engineering, 79(4), 13831390. doi:10.1016/j.jfoodeng.2006.04.019

Koziol, M. J. (1991). Afrosimetric estimation of threshold saponin concentration for bitterness in quinoa (chenopodium-quinoa willd). Journal of the Science of Food and Agriculture, 54(2), 211-219. doi:10.1002/ jsfa.2740540206

Kozioł, M. J. (1992). Chemical composition and nutritional evaluation of quinoa (chenopodium quinoa willd.) Journal of Food Composition and Analysis, 5(1), 3568. doi:10.1016/0889-1575(92)90006-6

Li, G. \& Zhu, F. (2017). Physicochemical properties of quinoa flour as affected by starch interactions. Food Chemistry, 221, 15601568. doi:10.1016/j.foodchem.2016.10.137

Lucas, T., Le Ray, D., \& Mariette, F. (2007). Kinetics of water absorption and solute leaching during soaking of breakfast cereals. Journal of Food Engineering, 80(2), 377-384. doi:10.1016/j.jfoodeng. 2005.11. 006
Machado, M. F., Oliveira, F. A. R., \& Cunha, L. M. (1999). Effect of milk fat and total solids concentration on the kinetics of moisture uptake by ready-to-eat breakfast cereal. International Journal of Food Science and Technology, 34(1), 47-57. doi:10. 1046/j.1365-2621.1999.00238.x

Montgomery, D. C. (1991). Design and analysis of experiments (N. Y. J. W. bibinitperiod Sons, Ed.).

Mota, C., Nascimento, A. C., Santos, M., Delgado, I., Coelho, I., Rego, A., ... Castanheira, I. (2016). The effect of cooking methods on the mineral content of quinoa (chenopodium quinoa), amaranth (amaranthus sp.) and buckwheat (fagopyrum esculentum). Journal of Food Composition and Analysis, 49, 57-64. doi:10.1016/ j.jfca.2016.02.006

Navruz-Varli, S. \& Sanlier, N. (2016). Nutritional and health benefits of quinoa (chenopodium quinoa willd.) Journal of Cereal Science, 69, 371-376. doi:10.1016/j. jcs.2016.05.004

Nickel, J., Spanier, L. P., Botelho, F. T., Gularte, M. A., \& Helbig, E. (2016). Effect of different types of processing on the total phenolic compound content, antioxidant capacity, and saponin content of chenopodium quinoa willd grains. Food Chemistry, 209, 139-143. doi:10.1016/j.foodchem.2016.04. 031

Pabis, S., Jayas, D. S., \& Cenkowski, S. (1998). Grain drying: theory and practice. John Wiley and Sons.

Peiretti, P. G., Gai, F., \& Tassone, S. (2013). Fatty acid profile and nutritive value of quinoa (chenopodium quinoa willd.) seeds and plants at different growth stages. $A n$ imal Feed Science and Technology, 183(12), 56-61. doi:10.1016/j.anifeedsci.2013.04. 012

Quispe-Fuentes, I., Vega-Galvez, A., Miranda, M., Lemus-Mondaca, R., Lozano, M., \& Ah-Hen, K. (2013). A kinetic approach to saponin extraction during washing of quinoa (chenopodium quinoa willd.) seeds. Journal of Food Process Engineering, 36(2), 202-210. doi:10.1111/j.17454530.2012.00673.x 
Ridout, C. L., Price, K. R., Dupont, M. S., Parker, M. L., \& Fenwick, G. R. (1991). Quinoa saponins-analysis and preliminary investigations into the effects of reduction by processing. Journal of the Science of Food and Agriculture, 54 (2), 165-176.

Ruales, J. \& Nair, B. M. (1993). Saponins, phytic acid, tannins and protease inhibitors in quinoa (chenopodium-quinoa, willd) seeds. Food Chemistry, 48(2), 137-143. doi:10 . 1016/0308-8146(93)90048-K

San Martin, R. \& Briones, R. (2000). Quality control of commercial quillaja (quillaja saponaria molina) extracts by reverse phase HPLC. Journal of the Science of Food and Agriculture, 80(14), 2063-2068.

Srichuwong, S., Curti, D., Austin, S., King, R., Lamothe, L., \& Gloria-Hernandez, H. (2017). Physicochemical properties and starch digestibility of whole grain sorghums, millet, quinoa and amaranth flours, as affected by starch and non-starch constituents. Food Chemistry, 233, 1-10. doi:10.1016/j.foodchem.2017.04.019

Torrez Irigoyen, R. M. \& Giner, S. A. (2014). Drying-toasting kinetics of presoaked soybean in fluidised bed. experimental study and mathematical modelling with analytical solutions. Journal of Food Engineering, 128, 31-39. doi:10.1016/j.jfoodeng. 2013. 12.009

van Boekel, M. A. J. S. (2008). Kinetic modeling of food quality: a critical review. Comprehensive Reviews in Food Science and Food Safety, 7(1), 144-158. 12 World Congress of Food Science and Technology, Chicago, IL, JUL 16-20, 2003. doi:10.1111/j.15414337.2007.00036.x

Varzakas, T. H., Leach, G. C., Israilides, C. J., \& Arapoglou, D. (2005). Theoretical and experimental approaches towards the determination of solute effective diffusivities in foods. Enzyme and Microbial Technology, 37(1), 29-41. doi:10.1016/j.enzmictec. 2004.06.015

Vega-Galvez, A., Miranda, M., Vergara, J., Uribe, E., Puente, L., \& Martinez, E. A. (2010). Nutrition facts and functional potential of quinoa (chenopodium quinoa willd.), an ancient andean grain: a review.
Journal of the Science of Food and Agriculture, 90(15), 2541-2547. doi:10.1002/jsfa. 4158

$$
\text { IJFS | October } 2018 \text { | Volume } 7 \text { | pages 76-88 }
$$

